\title{
Automatic control system of automobile suspension Yang $\mathrm{Li}^{1, \mathrm{a}^{*}}$, Guo Li ${ }^{1, \mathrm{~b}}$ and Qianrong Zhang ${ }^{1, \mathrm{c}}$ \\ ${ }^{1}$ Automation School, University of Science and Technology in Beijing, Beijing, China

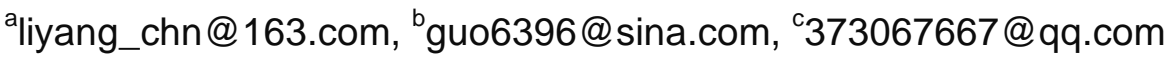

Keywords: Active Suspension; Pitch and Roll; Fuzzy Control; Sliding Mode Control Abstract. In this paper, the fuzzy control strategy based on the sliding mode control scheme of active suspension is added. During the simulation section, passive suspension model, the sliding mode control model of active suspension and the fuzzy sliding mode control model of active suspension were established. In the MATLAB/Simulink software, the simulation results verify the robustness and stability of the control strategy.

\section{Introduction}

The suspension system and its control method are always being concerned in the field of research and development. Whether the suspension system and its control method are developed or not, has an important indicator to check the safety of the vehicles, stability of the car and the comfort of the drivers. Therefore, the research and promotion of the active suspension and its control strategy is a difficult problem in the field of automobile research, and also the important issue of the automobile industry in our country and even the world.

\section{Vehicle Suspension mathematical model}

White noise signal through a low-pass filter output the road excitation. By the white noise signal, the road surface power spectrum density expression can get the time domain expression of road roughness.

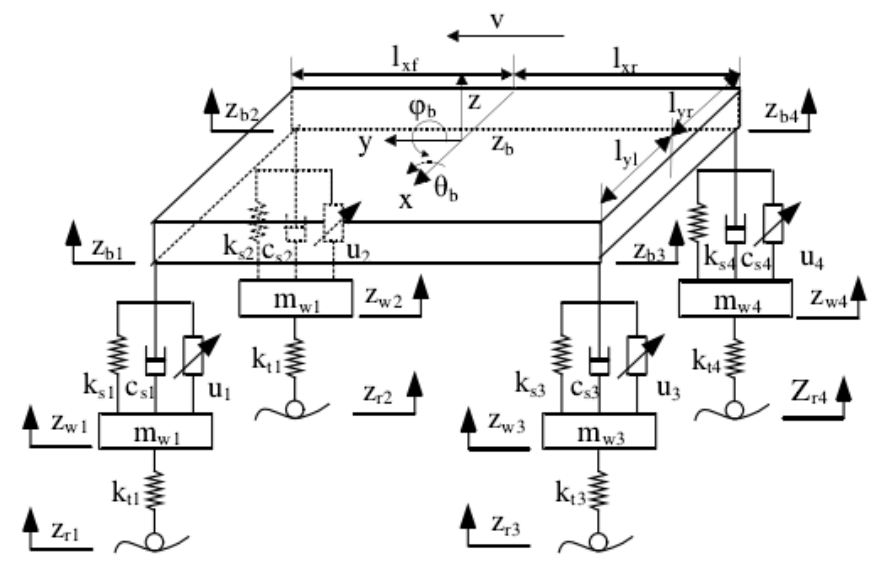

Fig.1 Vehicle dynamic model of 7 degree of freedom

Vehicle suspension system is a complicated system. In this paper, the vehicle suspension model with 7 degrees of freedom is used. As shown in Fig.1.

\section{Design of sliding mode controller for active suspension}

The displacement and acceleration of the vehicle suspension system with 7 degrees of freedom are selected as state variables:

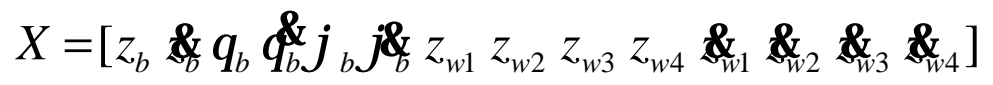

Control input matrix $U=\left[\begin{array}{llll}u_{1} & u_{2} & u_{3} & u_{4}\end{array}\right]^{T} \quad$,Pavement excitation $\operatorname{matrix} Z_{r}=\left[\begin{array}{llll}z_{r 1} & z_{r 2} & z_{r 3} & z_{r 4}\end{array}\right]^{T}$. 
The state equation and the switching equation of active suspension system

$$
\left\{\begin{array}{c}
X^{\alpha}=A^{\prime} X+B^{\prime} U \\
s^{\prime}=C^{\prime} X^{\prime}
\end{array}\right.
$$

When designing the switching function, temporarily ignore the perturbation. When the system enters the sliding mode $s^{\prime}=0, \mathbb{\&}=0$, The sliding mode motion equation :

$$
\mathrm{X}_{1}^{\mathcal{Q}}=\left(A_{11}^{\prime}-A_{12}^{\prime} C_{2}^{\prime-1} C_{1}^{\prime}\right) X_{1}^{\prime}
$$

Let $K=C_{2}^{\prime-1} C_{1}^{\prime}$,Assuming the system poles $P=\left[\lambda_{1} \mathrm{~L} \lambda_{10}\right]^{T}=[-1 \mathrm{~L}-10]^{T}$,

$$
K=\operatorname{place}\left(A_{11}^{\prime}, A_{12}^{\prime}, P\right), C_{1}=\left[C_{1}^{\prime} C_{2}^{\prime}\right]=\left[C_{2}^{\prime} K C_{2}^{\prime}\right]=C_{2}^{\prime}\left[K I_{4}\right], C_{2}^{\prime}=I_{4}, C^{\prime}=C^{\prime} T
$$

Using Sequential starting mode. Speed reaching law $\delta=-\varsigma \operatorname{sgn}(\mathrm{s})$, Meet the requirements of sliding mode control for accessibility and existence:

$$
\frac{1}{2} \frac{d}{d t} s^{2} \leq-\xi|s| \Rightarrow s \& \leq-\xi|s|, \xi>0
$$

The sliding mode control force for the multiple input system of the vehicle suspension is

$$
u_{\mathrm{i}}=-\left(c_{\mathrm{i}} b_{\mathrm{i}}\right)^{-1}\left[c_{\mathrm{i}} A X+\sum_{\mathrm{i}=1}^{\mathrm{i}-1} c_{\mathrm{i}} b_{\mathrm{i}} u_{\mathrm{ieq}}+c_{\mathrm{i}} F Z_{r}\right]+\varepsilon_{\mathrm{i}} \operatorname{sgn}\left(s_{\mathrm{i}}\right)
$$

\section{Design of fuzzy sliding mode controller for active suspension}

The schematic diagram of fuzzy sliding mode control is shown in Fig.2. Assuming the input of the fuzzy controller is $S$ and $S C$, they are fuzzy quantity of $s$ and \&in sliding mode controller. The fuzzy quantity of $\varepsilon$ is $E, E$ is the output of the fuzzy controller. The domain value for the definition of fuzzy theory is $S=S C=E=\{-3,-2,-1,0,1,2,3\}$.Using the Area split method, select the Triangle membership function as the membership function of the input variable $S, S C$ and the output variable $E$.The fuzzy controller is built in MATLAB/Simulink, is shown in Fig.3.

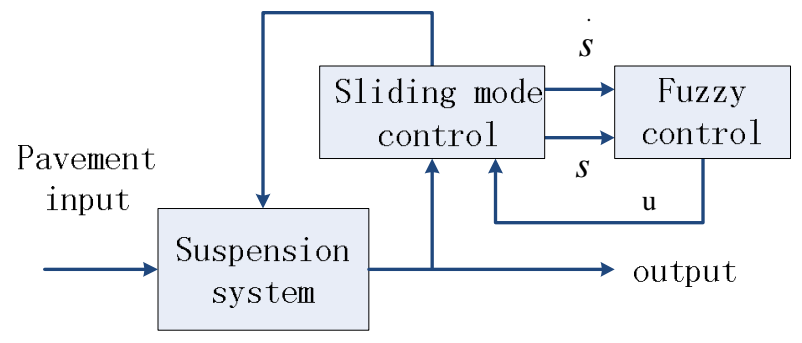

Fig.2 Schematic diagram of fuzzy sliding mode control

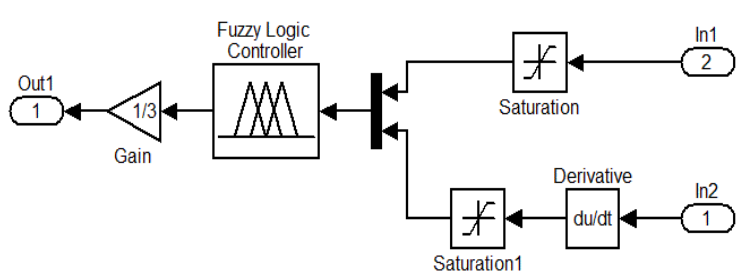

Fig.3 Fuzzy controller model

Using fuzzy control to determine the switching coefficient $\varepsilon_{i}$ of the sliding mode control, use $\varepsilon_{f u z z y_{i}}$ instead of $\varepsilon_{i}$.the control quantity of fuzzy sliding mode controller can be obtained By Eq.5.

$$
u_{\mathrm{i}}=-\left(c_{\mathrm{i}} b_{\mathrm{i}}\right)^{-1}\left[c_{\mathrm{i}} A X+\sum_{\mathrm{i}=1}^{\mathrm{i}-1} c_{\mathrm{i}} b_{\mathrm{i}} u_{\mathrm{i} e q}+c_{\mathrm{i}} F Z_{r}\right]+\varepsilon_{f u z z y i} \operatorname{sgn}\left(s_{\mathrm{i}}\right)
$$

Where $\varepsilon_{f u z z y i}$ is the output of the fuzzy sliding mode controller.

\section{Vehicle suspension control system simulation}

The establishment of simulation model of passive suspension. In MATLAB/Simulink, the simulation model of the pavement input is built into sub modules. Active control amount $U=0$.

Get, $X=A X+F Z_{r}$ 
The simulation model is established by the Eq.7, is shown in Fig.4.

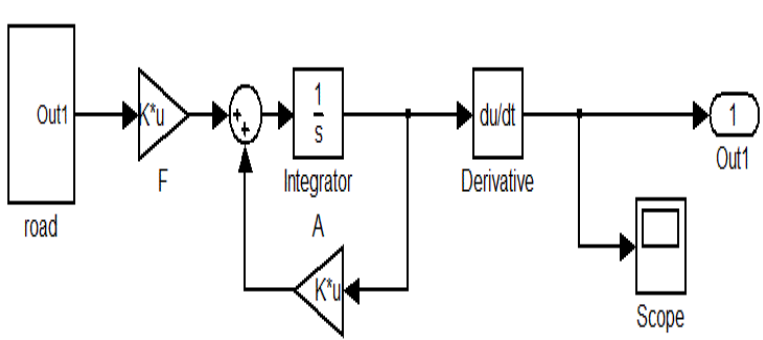

Fig.4 Passive suspension Simulink simulation model

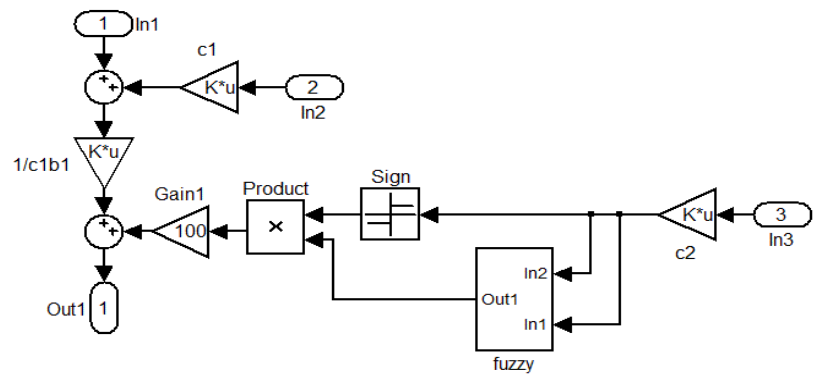

Fig.5 Simulink model of Fuzzy sliding mode controller

Fuzzy sliding mode control simulation model for active suspension. In this paper, we study the control of the vehicle suspension sliding mode variable structure algorithm using the sequential start mode. That is starting in sequence from $u_{1}$ to $u_{4}$.the control quantity of fuzzy sliding mode controller is shown in Eq.6, and the Fuzzy sliding mode control simulation model of active suspension is established in Simulink, the logical relationship of the order is shown in Fig.6.

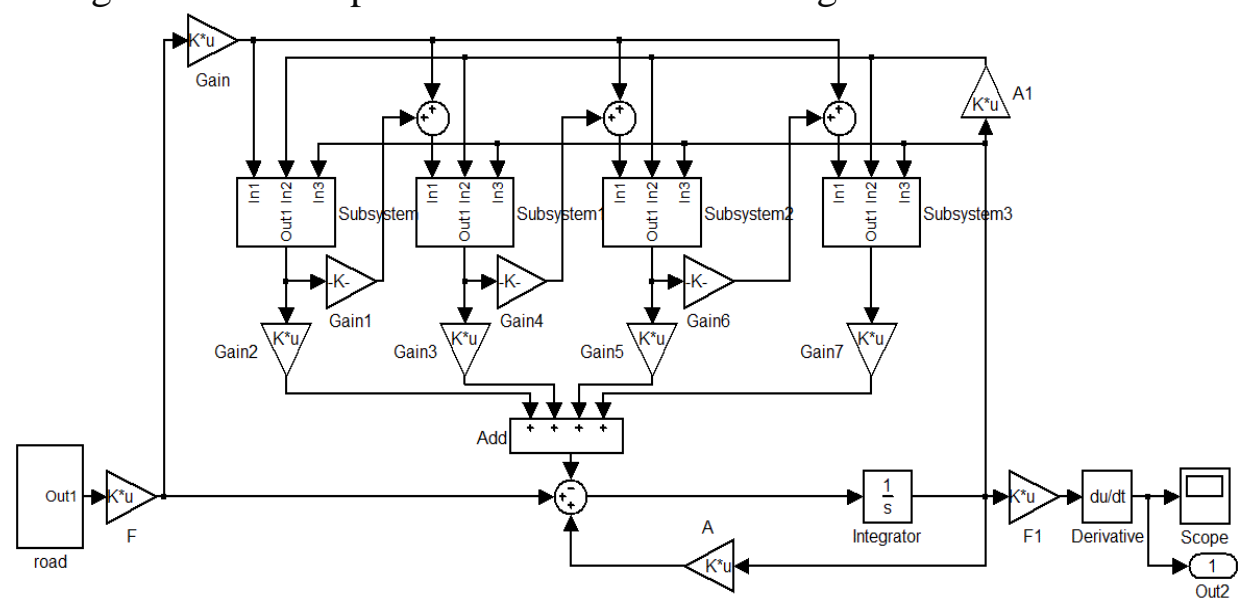

Fig.6 Simulink simulation model of active suspension sliding mode control

In the Fig.6,the simulation model contains the sub module of the controller. Fuzzy sliding mode controller model is shown in Fig.5.

Simulation results and analysis of fuzzy sliding mode control strategy for active suspension. By the Fig. 7 to the Fig.10, it can be seen that the fuzzy sliding mode control method is more effective than the sliding mode control method to suppression of vibration, and reduce the amplitude of the curve, to some extent, the inherent chattering problem of sliding mode control is overcome. In the simulation of vehicle suspension active control, it shows more superior performance.

From the table 1, the main passive suspension simulation results of the contrast data can be seen, for the body acceleration, the pitch angle acceleration and the side dip angle acceleration, which means the vehicle ride comfort. The sliding mode control is decreased by $35.75 \%, 34.64 \%$ and $33.65 \%$ compared with the passive suspension control, and the fuzzy control is decreased by about $20 \%$ compared with the sliding mode control, significantly improved body vertical acceleration, pitch and roll, improves the ride comfort. 
Table1 Comparison of simulation results of main passive suspension

\begin{tabular}{|c|c|c|c|}
\hline Performance index (Root mean square) & $\begin{array}{c}\text { Passive } \\
\text { suspension }\end{array}$ & $\begin{array}{c}\text { Sliding mode } \\
\text { control }\end{array}$ & $\begin{array}{c}\text { Fuzzy sliding } \\
\text { mode control }\end{array}$ \\
\hline Vertical displacement $(\mathrm{m})$ & 0.1013 & 0.0664 & 0.0503 \\
\hline Vertical acceleration $\left(\mathrm{m} / \mathrm{s}^{2}\right)$ & 2.2537 & 1.4479 & 1.2395 \\
\hline Pitch angular acceleration $\left(\mathrm{rad} / \mathrm{s}^{2}\right)$ & 0.1022 & 0.0668 & 0.0506 \\
\hline side dip angle acceleration $\left(\mathrm{rad} / \mathrm{s}^{2}\right)$ & 0.3881 & 0.2575 & 0.1951 \\
\hline
\end{tabular}

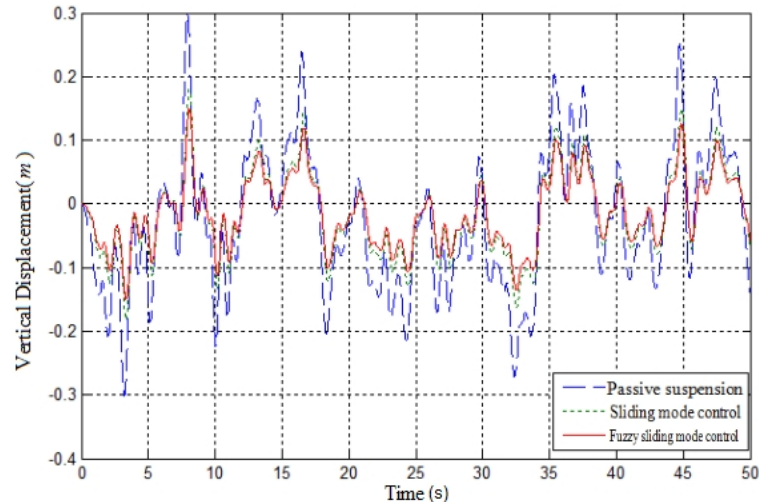

Fig.7 Comparison of the vertical displacement

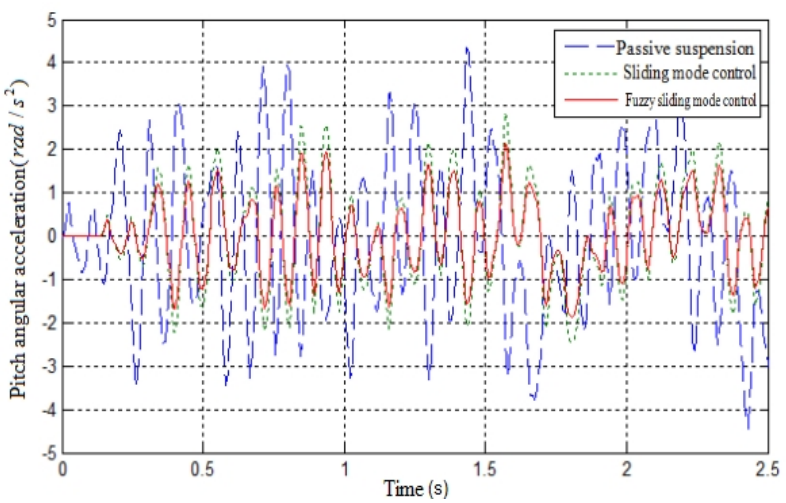

Fig.9 Comparison of the pitch angle acceleration

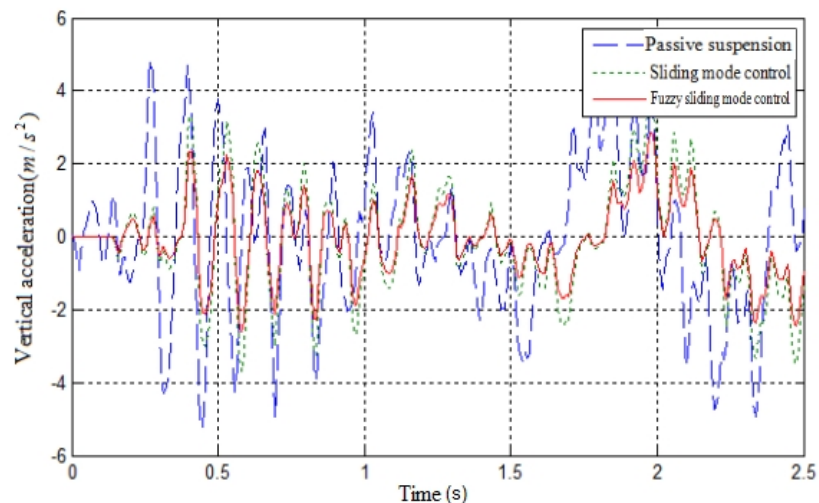

Fig.8 Comparison of the body acceleration

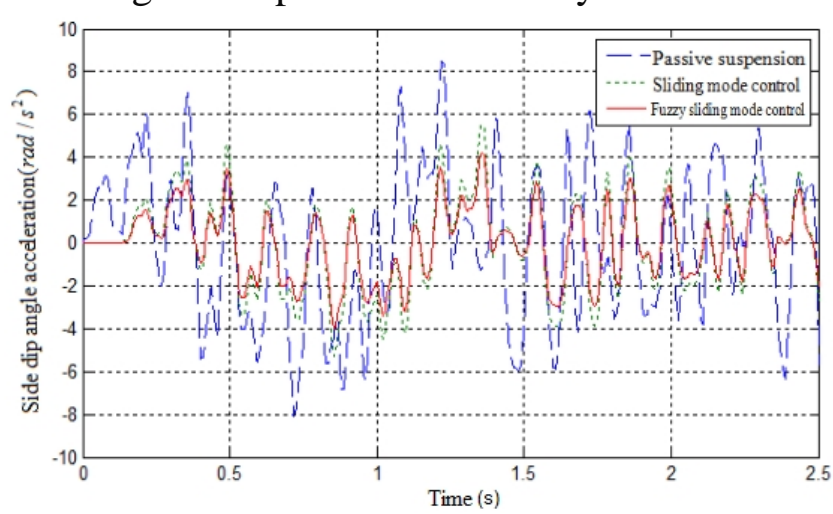

Fig.10 Comparison of the side-slip angle acceleration

\section{Conclusions}

In this paper, a fuzzy sliding mode controller is designed, which uses its strong robustness, the motion of the vehicle active suspension system is controlled. The uncertainty of the pavement and the system is suppressed effectively, and the sensitivity of the suspension system is significantly reduced, and the active regulation of the body posture is realized.

\section{Acknowledgments}

Fundamental Research Funds for the Central Universities 06105053

\section{References}

[1] Shaohua Wang, Long Chen, Xiaoqiang Sun. A multimode switching control mode for semi-active air suspension[J],Journal of Jiangsu University: Natural Science Edition,2013, 34(6):637-642.In Chinese

[2] Min Fang, Jun Wang, Wuwei Chen. Adaptive LQG Control for Automotive Semi-active Suspension [J],Automotive Engineering,1997,19(4): 200-205.In Chinese 
[3] Zifan Fang, Zhaoxiang Deng. A Review of Recent Advances in Research and Development on Vehicle Semi-Active Suspension Systems[J].Journal of Chongqing University: Natural Science Edition, 2003, 26(1): 104-108.In Chinese

[4] Yoshimura T. Active suspension of vehicle systems using fuzzy logic[J]. International journal of systems science, 1996, 27(2): 215-219.

[5] Rao M V C, Prahlad V. A tunable fuzzy logic controller for vehicle-active suspension systems[J]. Fuzzy sets and systems,1997,85(1):11-21. 